\title{
Fundamental limitation of electrocatalytic methane conversion to methanol
}

Arnarson, Logi; Schmidt, Per Simmendefeldt; Pandey, Mohnish; Bagger, Alexander; Thygesen, Kristian Sommer; Stephens, Ifan E. L.; Rossmeisl, Jan

Published in:

Physical Chemistry Chemical Physics

Link to article, DOI:

$10.1039 / \mathrm{c} 8 \mathrm{cp} 01476 \mathrm{k}$

Publication date:

2018

Document Version

Peer reviewed version

Link back to DTU Orbit

Citation (APA):

Arnarson, L., Schmidt, P. S., Pandey, M., Bagger, A., Thygesen, K. S., Stephens, I. E. L., \& Rossmeisl, J. (2018). Fundamental limitation of electrocatalytic methane conversion to methanol. Physical Chemistry Chemical Physics, 20(16), 11152-11159. https://doi.org/10.1039/c8cp01476k

\section{General rights}

Copyright and moral rights for the publications made accessible in the public portal are retained by the authors and/or other copyright owners and it is a condition of accessing publications that users recognise and abide by the legal requirements associated with these rights.

- Users may download and print one copy of any publication from the public portal for the purpose of private study or research.

- You may not further distribute the material or use it for any profit-making activity or commercial gain

- You may freely distribute the URL identifying the publication in the public portal 


\title{
Journal Name
}

\section{ARTICLE TYPE}

Cite this: DOI: 10.1039/xxxxxxxxxx

\section{Fundamental Limitation of Electrocatalytic Methane Conversion to Methanol}

\author{
Logi Arnarson ${ }^{* a}$, Per S. Schmidt ${ }^{b}$, Mohnish Pandey ${ }^{b}$, Alexander Bagger ${ }^{a}$, Kristian S. \\ Thygesen $^{b}$, Ifan E. L. Stephens ${ }^{c}$ and Jan Rossmeis| ${ }^{* a}$
}

Received Date

Accepted Date

DOI: 10.1039/xxxxxxxxxx

www.rsc.org/journalname

\begin{abstract}
The electrochemical oxidation of methane to methanol at remote oil fields where methane is flared is the ultimate solution to harness this valuable energy resource. In this study we identify a fundamental surface catalytic limitation of this process in terms of a compromise between selectivity and activity, as oxygen evolution is a competing reaction. By investigating two classes of materials, rutile oxides and two-dimensional transition metal nitrides and carbides (MXenes), we find a linear relationship between the energy needed to activate methane, i.e. to break the first $\mathrm{C}-\mathrm{H}$ bond, and oxygen binding energies on the surface. Based on a simple kinetic model we can conclude that in order to obtain sufficient activity oxygen has to bind weakly to the surface but there is an upper limit to retain selectivity. Few potentially interesting candidates are found but this relatively simple description enables future large scale screening studies for more optimal candidates.
\end{abstract}

\section{Introduction}

At oil fields around the globe, an estimated 150 billion cubic meters of methane $\left(\mathrm{CH}_{4}\right.$, natural gas) are burned as waste, every day, corresponding to $20 \%$ of the U.S. gas consumption 1 . Consequently, $\mathrm{CO}_{2}$ is released into the atmosphere contributing with $3 \%$ of the global $\mathrm{CO}_{2}$ emissions ${ }^{2]}$ and an enormous amount of energy $\left(30 \mathrm{EJ}^{2}\right)$ is lost annually. Methane has 25 times the global warming potential of carbon dioxide, which is why it is usually burned instead of released directly ${ }^{3}$. This happens at remotely located oil fields where there is insufficient infrastructure to store and transport the gaseous methane. One attractive solution to this problem would be to develop a remote-deployable technology which can oxidise methane into a liquid fuel, such as methanol, that would fit better into the existing infrastructure. This has been a major challenge within the field of heterogeneous catalysis for decades 4 49. However, the direct routes to produce methanol from methane are inefficient, require high pressures, are unselective or require oxidants such as $\mathrm{H}_{2} \mathrm{O}_{2}$, for which transportation to remote locations is extremely challenging. To yield higher efficiencies, more complex, indirect multistage processes can be utilized but has drawbacks in form of requiring higher temperatures and pressures and consequently extended infras-

\footnotetext{
${ }^{a}$ Nano-Science Center, Department of Chemistry, University of Copenhagen, Universitetsparken 5, Copenhagen, Denmark.

${ }^{b}$ Center for Atomic-scale Materials Design (CAMD), Technical University of Denmark, DK-2800 Kongens Lyngby, Denmark.

${ }^{c}$ Department of Materials, Imperial College London, Exhibition Road, London SW7 $2 A Z, U K$.

* Corresponding author, Jan.Rossmeisl@chem.ku.dk.
}

tructure. In contrast, the electrochemical oxidation of methane to methanol could be far more attractive. A schematic of an electrochemical fuel cell producing methanol is shown in Fig. 1 requiring only methane, water and oxygen. The overall reaction is

$$
\begin{aligned}
& \mathrm{CH}_{4}(g)+\frac{1}{2} \mathrm{O}_{2}(g) \rightarrow \mathrm{CH}_{3} \mathrm{OH}(l) \\
& \Delta G^{0} \cong-116.0 \mathrm{~kJ} / \mathrm{mol}
\end{aligned}
$$

At the anode, $\mathrm{CH}_{4}$ is oxidised to methanol according to:

$$
\begin{aligned}
& \mathrm{CH}_{4}+\mathrm{H}_{2} \mathrm{O} \rightarrow \mathrm{CH}_{3} \mathrm{OH}+2\left(\mathrm{H}^{+}+\mathrm{e}^{-}\right) \\
& \Delta G^{0} \cong 121.2 \mathrm{~kJ} / \mathrm{mol} \\
& E_{\text {cell }}^{0} \cong-0.63 \mathrm{~V}(\mathrm{RHE})
\end{aligned}
$$

whereas at the cathode, $\mathrm{O}_{2}$ is reduced to $\mathrm{H}_{2} \mathrm{O}$ :

$$
\begin{aligned}
& \frac{1}{2} \mathrm{O}_{2}+2\left(\mathrm{H}^{+}+\mathrm{e}^{-}\right) \rightarrow \mathrm{H}_{2} \mathrm{O} \\
& \Delta G^{0} \cong-228.6 \mathrm{~kJ} / \mathrm{mol} \\
& E_{\text {cell }}^{0} \cong 1.18 \mathrm{~V}(\mathrm{RHE})
\end{aligned}
$$

Rather than consuming energy, such a device could in principle produce energy to harness in the form of electricity, in addition to the liquid fuel methanol. This is the ultimate solution for tapping into the wasted methane. The device would be portable with easy scale up and the produced liquid methanol could be easily stored 


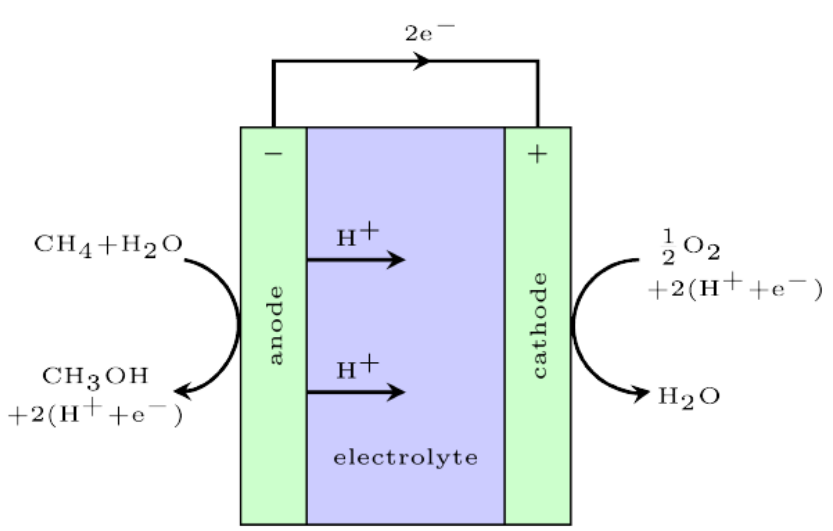

Fig. 1 Schematic figure of an electrochemical fuel cell converting $\mathrm{CH}_{4}$ and $\mathrm{O}_{2}$ into $\mathrm{CH}_{3} \mathrm{OH}$ and $\mathrm{H}_{2} \mathrm{O}$

in tanks in areas without sufficient pipelines. In this study we identify the fundamental surface catalytic limitations for methane oxidation to methanol. The challenge is to produce methanol at high rates and selectivity requiring at least three criteria to be fulfilled: 1) Activate $\mathrm{CH}_{4}$ and form $\mathrm{CH}_{3} \mathrm{OH}$, 2) Avoid $\mathrm{O}_{2}$ evolution and 3) Avoid $\mathrm{CH}_{3} \mathrm{OH}$ oxidation to the more thermodynamically favourable product, $\mathrm{CO}_{2}$.

As for $\mathrm{CO}_{2}$ reduction, the key component in controlling the performance of electrochemical devices is the interface between the electrolyte and electrode. Typically, metal electrocatalysts produce $\mathrm{CO}_{2}$ by oxidising methane. A number of reports in the literature have been devoted to the oxidation of methane to methanol at low temperatures (i.e. $100^{\circ} \mathrm{C}$ or below), via (i) an indirect method or (ii) a direct method. In the indirect method, the same electrode acts as cathode and anode, reducing $\mathrm{O}_{2}$ and at the same time oxidising methane ${ }^{10}[11$. Earlier studies suggest that this proceeds by the formation of the superoxide anion via an "outersphere" solution phase step 10 : $\mathrm{O}_{2}+\mathrm{e}^{-} \rightarrow \mathrm{O}_{2}^{-}$. This highly reactive species would abstract a proton from methane, allowing it to be oxidised. However, it would be far more attractive to oxidise methane directly, avoiding its potentially explosive mixture with $\mathrm{O}_{2}$.

Upon oxidising methane, reactive metals such as Pt produce close to $100 \% \mathrm{CO}_{2} \cdot \frac{12}{12}$ On the other hand, oxides seem to be able to produce methanol; for instance $\mathrm{V}_{2} \mathrm{O}_{5}$ on $\mathrm{SnO}_{x}$ produces $60 \%$ methanol at a current density of $4 \mathrm{~mA} \mathrm{~cm}^{-2}$ at $100^{\circ} \mathrm{C} 13$. Methanol production peaked at a cell potential of $0.9 \mathrm{~V}$, i.e. equivalent to an energy input of $\sim 170 \mathrm{~kJ} / \mathrm{mol}$; however, this input is only $25 \%$ of the Gibbs free energy released upon the complete oxidation of methanol to $\mathrm{CO}_{2}$. In order for this to be industrially viable, the current density has to be increased, selectivity improved and the overpotential minimized.

The catalyst material needs to bind oxygen weakly or as a radical, to have the driving force for oxidizing methane. The consequence is that the potential needed to run the reaction: $\mathrm{H}_{2} \mathrm{O}+* \rightarrow * \mathrm{O}+2\left(\mathrm{H}^{+}+\mathrm{e}^{-}\right)$is high, but at the same time below the potential necessary to catalyse the oxygen evolution. The activity of the methanol production therefore depends on having available $* \mathrm{O}$ species to react with methane but in order to ensure se- lectivity towards the methanol reaction pathway the coverage of these $* \mathrm{O}$ species should be kept low and the catalyst should have a high oxygen vacancy formation energy to avoid $\mathrm{O}_{2}$ formation. Consequently, it is not a precondition that the bare surface has to be an effective catalyst for thermal methane activation since the reactivity is determined by the adsorption energy of $* \mathrm{O}$, which is obtained via electrochemical water splitting.

Furthermore it poses a challenge to selectively form methanol versus the more thermodynamically favoured products, in particular $\mathrm{CO}_{2}$ according to:

$$
\begin{aligned}
& \mathrm{CH}_{4}(g)+2 \mathrm{O}_{2}(g) \rightarrow \mathrm{CO}_{2}(g)+\mathrm{H}_{2} \mathrm{O}(g) \\
& \Delta G \cong-801 \mathrm{~kJ} / \mathrm{mol} .
\end{aligned}
$$

However, based on the work of Behm and co-workers on similar reactions, we propose that accelerated mass transport of methanol away from the surface could prevent its oxidation 14 . This could be controlled by judicious electrode structuring and mass transport as we do not expect that the further oxidation of methanol can be avoided by controlling the catalyst material. In this study we therefore focus on how to obtain methanol and further oxidation reactions will be considered in future work.
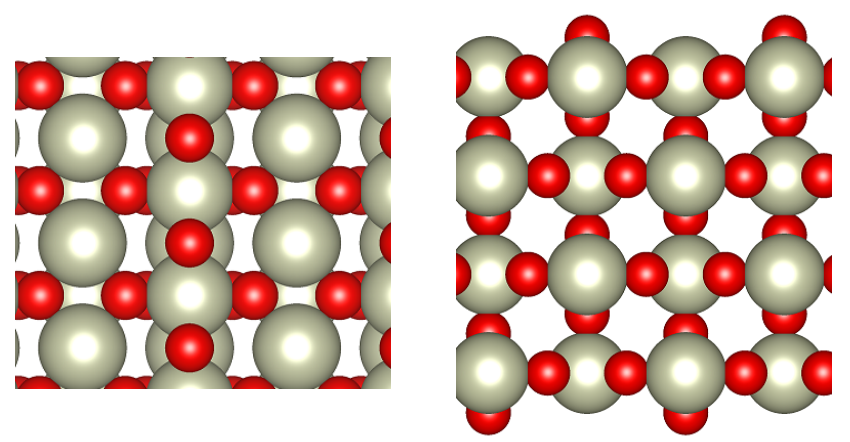

(a)
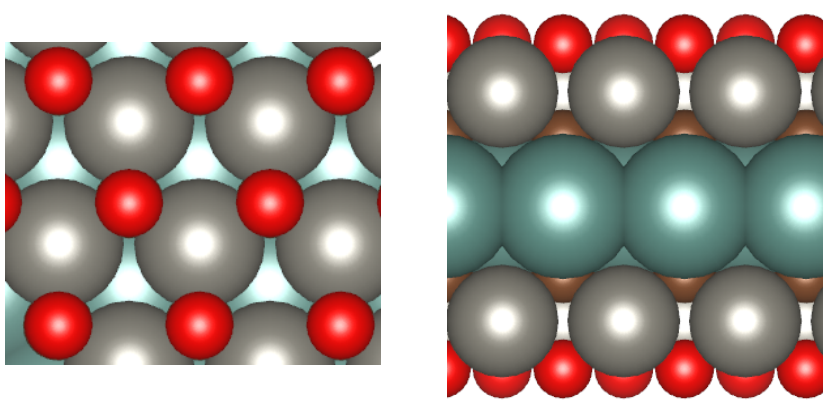

(b)

Fig. 2 Top and side view of the a) (110) rutile transition metal oxides and b) MXenes. Oxygen atoms are red, metal atoms light grey and green and carbon atoms are brown.

In this study we investigate two different classes of surfaces for methanol production. The (110) surface of rutile transition metal oxides, $\mathrm{MeO}_{2}$ (Me; a transition metal atom), and monolayer MXenes of the $\mathrm{AB}_{2} \mathrm{C}_{2} \mathrm{O}_{2}$ type (A, B: two transition metal atoms). MXenes is a new class of two-dimensional materials comprising carbides and nitrides of transition metals. MXenes have shown 
promise for various applications in lithium/sodium ion batteries and as HER catalysts $15\left[16\right.$. MXenes come in various types; $\mathrm{M}_{2} \mathrm{X}$, $\mathrm{M}_{3} \mathrm{X}_{2}, \mathrm{M}_{2} \mathrm{XA}_{2}, \mathrm{M}_{3} \mathrm{X}_{2} \mathrm{~A}_{2}, \mathrm{M}_{4} \mathrm{X}_{3} \mathrm{~A}_{2}$ etc., where $\mathrm{M}$ refers to the transition metal, $\mathrm{X}$ refers to carbon or nitrogen and A refers to the functional group present on the surface $(\mathrm{O}, \mathrm{OH}$ or $\mathrm{F})$. Additionally, all the MXenes considered here are metallic resulting in better electron transport properties under operating conditions compared to the mostly semiconducting rutile oxides. In this study, we limit ourselves to the metallic $\mathrm{AB}_{2} \mathrm{C}_{2} \mathrm{O}_{2}$ type, which is shown in Fig. 2 . The rationale to use $\mathrm{O}$ as the functional group is the solvothermal synthesis of MXenes under acidic condition where $\mathrm{O}$ and $\mathrm{OH}$ are present to passivate the surface 17 . Previous studies have found that functionalization with $\mathrm{O}$ is thermodynamically preferred 18 . The same study investigated the use of some of the MXenes for HER. They found that the hydrogen adsorption energy varied by up to $0.5 \mathrm{eV}$ depending on the number of metal layers suggesting that catalytic activity can be tuned by controlling layer thickness. Given the possibility to tune the number of layers and the different choices of $\mathrm{M}, \mathrm{X}$ and $\mathrm{A}$, this class of materials is vast. In this study we limit ourselves to seven candidates.

\section{Results and discussion}

The first part of the electrochemical production of methanol from methane is to split water by means of electrochemistry in a water electrolyser to provide an adsorbed oxygen atom. This is also known as the first two elementary reactions in the oxygen evolution reaction (OER). All four reactions of the OER are:

$$
\begin{aligned}
*+2 \mathrm{H}_{2} \mathrm{O} & \rightarrow * \mathrm{OH}+\mathrm{H}_{2} \mathrm{O}+\left(\mathrm{H}^{+}+\mathrm{e}^{-}\right) \\
& \rightarrow * \mathrm{O}+\mathrm{H}_{2} \mathrm{O}+2\left(\mathrm{H}^{+}+\mathrm{e}^{-}\right) \\
& \rightarrow * \mathrm{OOH}+3\left(\mathrm{H}^{+}+\mathrm{e}^{-}\right) \\
& \rightarrow *+\mathrm{O}_{2}+4\left(\mathrm{H}^{+}+\mathrm{e}^{-}\right)
\end{aligned}
$$

where $*$ represents an active site on the surface. In Fig. 3 the full OER energetics, according to reactions (5)-(8), for a range of different $\mathrm{MeO}_{2}$ (110) surfaces is shown. The stability of the $* \mathrm{O}$ intermediate is of importance for methanol production since this is the oxygen atom oxidizing methane to methanol. It is clear from Fig. 3(a) that the different materials provide an oxygen atom with vastly different degree of reactivity. For $\mathrm{NbO}_{2}$ it is energetically advantageous to form $* \mathrm{O}$ by $-1.41 \mathrm{eV}$ whereas it costs $3.54 \mathrm{eV}$ on $\mathrm{PtO}_{2}$. In Fig. 3(b) the same free energy diagram is shown for the MXenes. Different reactivities are found from this class of materials as well.

The energies associated with each individual reaction is defined from the reaction equations, Eq. (5)-(8):

$$
\begin{aligned}
& \Delta G_{1}=G_{\mathrm{O}_{2}}-G_{\mathrm{OOH}} \\
& \Delta G_{2}=G_{\mathrm{OOH}}-G_{\mathrm{O}} \\
& \Delta G_{3}=G_{\mathrm{O}}-G_{\mathrm{OH}} \\
& \Delta G_{4}=G_{\mathrm{OH}}
\end{aligned}
$$

The potential limiting step for the OER is the maximum of the reaction energies $\Delta G_{1-4} \cdot \frac{19}{19}$ Since the intermediates $(\mathrm{OH}, \mathrm{O}, \mathrm{OOH})$ all bind to the surface via the oxygen atom their adsorption energies are correlated and cannot be tuned independently by changing the catalyst material. There exist a universal scaling relation so the energy difference between $G_{\mathrm{OH}}$ and $G_{\mathrm{OOH}}$ is $3.2 \mathrm{eV} \pm$ $0.2 \mathrm{eV} . \frac{1620}{16}$ Furthermore, using that $G_{\mathrm{OH}} \simeq 1 / 2 G_{\mathrm{O}}$ allows for plotting the potential needed to drive the reaction as a function of a single intermediate adsorption energy. $\frac{19}{10}$ In Fig. 4 the OER activity volcano is plotted as a function of the descriptor $E_{\mathrm{O}}-E_{\mathrm{OH}}$ along with the data for the rutile oxides and MXenes. With a few exceptions, they all fall on the activity volcano with either $\Delta G_{3}=\Delta G_{4}$ (right leg) or $\Delta G_{2}$ (left leg) as the potential limiting step. The peak of the OER activity volcano is at $\sim 1.6 \mathrm{~V}$ with respect to a reversible hydrogen electrode (RHE) which is $\sim 0.4 \mathrm{~V}$ from the equilibrium potential giving rise to a minimum overpotential, $\eta_{O E R}$, of at least $\sim 0.4 \mathrm{~V}$ even for the ideal catalyst.

Possible candidates for methanol production must lie on the left leg of the volcano with $\Delta G_{2}$ as the potential limiting step, meaning that the energy needed to form $* \mathrm{OOH}$ is higher than the energy of forming $* \mathrm{OH}$ and $* \mathrm{O}$. Consequently, it is possible to apply a potential where either $* \mathrm{OH}$ or $* \mathrm{O}$ is present on the surface, depending on the voltage and the specific catalyst, without the adsorbed species spontaneously follow the OER pathway and form $\mathrm{O}_{2}$. The materials on the right leg of the volcano are all limited by (5), i.e. $* \mathrm{OH}$ formation: as long as the potential bias is sufficient to drive this step, the catalysts will evolve $\mathrm{O}_{2}$ at a significant rate. $\mathrm{IrO}_{2}$ and $\mathrm{RuO}_{2}$ are found to be the best OER catalysts i.e. are associated with the lowest overpotential in consensus with what is found experimentally and both are found to be on the left side of the OER volcano. 2122 of the MXenes, $\mathrm{WTi}_{2} \mathrm{C}_{2} \mathrm{O}_{2}$ and $\mathrm{TaHf}_{2} \mathrm{C}_{2} \mathrm{O}_{2}$ are found in close proximity to $\mathrm{IrO}_{2}$ and $\mathrm{RuO}_{2}$ ensuring a low overpotential and at the left leg of the volcano. Both $\mathrm{RhO}_{2}$ and $\mathrm{MoHf}_{2} \mathrm{C}_{2} \mathrm{O}_{2}$ are also found to be potentially interesting candidates despite appearing on the right side of the volcano but due to the intrinsic uncertainty in DFT calculations they should not be ruled out.

The second part of the overall reaction in Eq. (1) is a reaction between atomic oxygen on the metal oxide surface and methane, which is a purely thermal catalytic step. The reaction pathway consists of the following elementary reactions:

$$
\begin{aligned}
* \mathrm{O}+\mathrm{CH}_{4}(\mathrm{~g}) & \rightarrow * \mathrm{O} \cdots \mathrm{CH}_{4} \\
& \rightarrow *\left(\mathrm{OH} \cdots \mathrm{CH}_{3}\right) \\
& \rightarrow * \mathrm{CH}_{3} \mathrm{OH} \\
& \rightarrow *+\mathrm{CH}_{3} \mathrm{OH}(\mathrm{g})
\end{aligned}
$$

where $* \mathrm{O}$ in Eq. (13) is the same site as $* \mathrm{O}$ introduced in Eq. (6). The product of the reaction in Eq. (13) is an oxygen atom bonded to the active site and $\mathrm{CH}_{4}$ in the vicinity to it. Eq. (14) denotes the transition state and Eq. (15) is $\mathrm{CH}_{3} \mathrm{OH}$ bonded to the surface. Eq. (16) is the final state, which is the clean surface and gas phase methanol. The reaction is therefore found to proceed via the coupling of $\mathrm{CH}_{3}$ and a $\mathrm{OH}$ on the surface. This reaction 
(a)

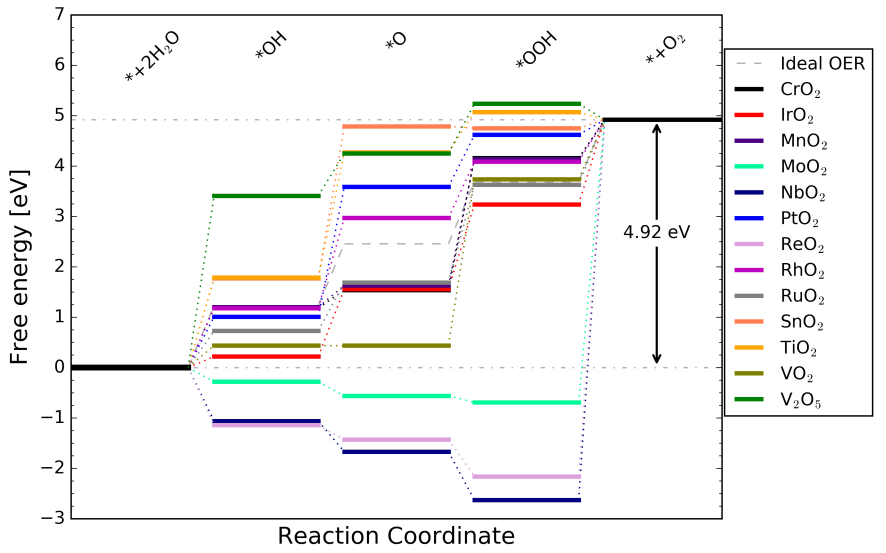

(b)

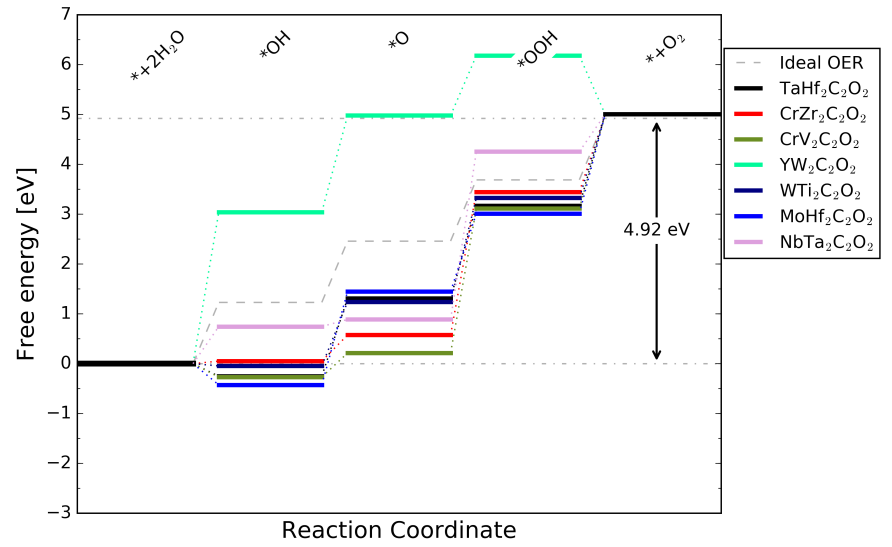

Fig. 3 OER free energy diagram for the (a) metal oxides and (b) MXenes following the reaction pathway of Eq. 5.-8.

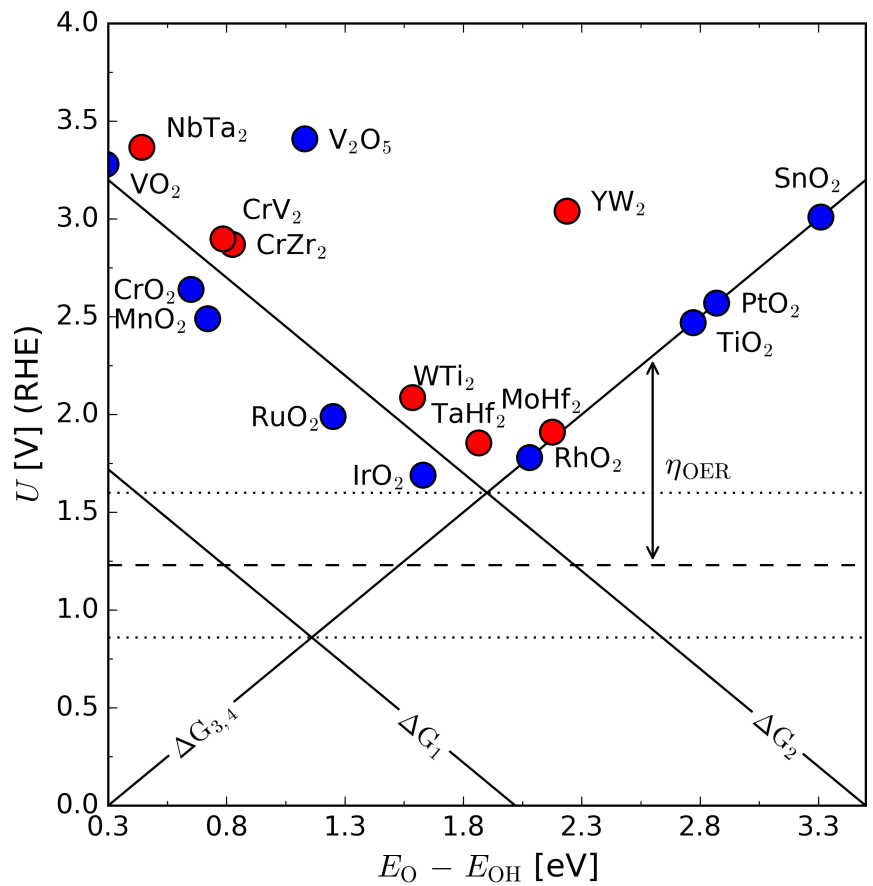

Fig. 4 The limiting potential and descriptor energy for the metal oxides (blue) and MXenes (red) plotted on the OER activity volcano.

pathway was established by carrying out Climbing Image Nudged Elastic Band (CI-NEB) calculations for $\mathrm{RhO}_{2}$ (see Fig. [5), $\mathrm{VO}_{2}$ and a few of the MXenes. In Fig. 5, images are shown along the pathway. The first image in Fig. 5 corresponds to $* \mathrm{O} \cdots \mathrm{CH}_{4}$ in Eq. (13) and the last to $* \mathrm{CH}_{3} \mathrm{OH}$ in Eq. (15). Image 3 in Fig. 5 is the transition state where the methane has delivered a single $\mathrm{H}$ atom to the $* \mathrm{O}$ site and $\mathrm{CH}_{3}$ is in the vicinity. This transition state is in consensus with what has been named the radical pathway, but for a different reaction, in a recent publication from Latimer et. al. 23 .

Analysis of the structure of the adsorbate in the transition state shows that the $\mathrm{CH}_{3}$ molecule exhibits planar geometry with all $\mathrm{H}-\mathrm{C}-\mathrm{H}$ bonding angles $\sim 120^{\circ}$. However, the geometry of the $\mathrm{CH}_{4}$

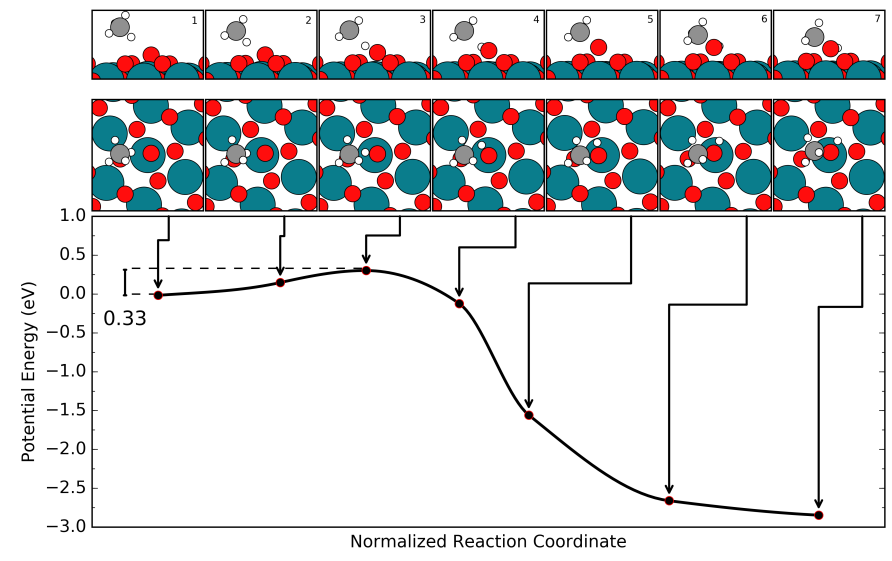

Fig. 5 Reaction pathway calculated using the Cl-NEB method on $\mathrm{RhO}_{2}$ for methane oxidation.

molecule is tetrahedral with all H-C-H bonding angles of $\sim 109.5^{\circ}$. This suggests that the energy required to break the first C-H bond, i.e. to activate methane, equals the energy needed to deliver a single $\mathrm{H}$ atom to the surface and form $\mathrm{CH}_{3}$ from $\mathrm{CH}_{4}$, i.e.:

$$
E_{\text {act }}^{\text {estimated }}=\left(E_{\mathrm{CH}_{3}(\mathrm{~g})}-E_{\mathrm{CH}_{4}(\mathrm{~g})}\right)+\left(E_{* \mathrm{OH}}-E_{* \mathrm{O}}\right)
$$

relating the activation energy to $\Delta G_{3}$ in Eq. (11). This corresponds to converting the sp3 hybridisation in $\mathrm{CH}_{4}$ to sp2 hybridisation in $\mathrm{CH}_{3}$ and the double bonded oxygen to the metal atom to a single bonded $\mathrm{OH}$ group on the surface. In Fig. 6t the activation energy of Eq. (17) is plotted with circles against the descriptor $E_{\mathrm{OH}}-E_{\mathrm{O}}$. With this model, all materials lie on a straight line. The activation energy calculated with the CI-NEB method according to

$$
E_{\text {act }}^{\text {calculated }}=E_{*\left(\mathrm{OH} \cdots \mathrm{CH}_{3}\right)}-E_{* \mathrm{O} \cdots \mathrm{CH}_{4}}
$$

is marked with squares in Fig. 6 Marked with triangles is an approximated calculated activation energy using the already found CI-NEB path and unit cell of $\mathrm{RhO}_{2}$ for all the other materials of the $\mathrm{MeO}_{2}$ type (except $\mathrm{VO}_{2}$ ). The approximated and calculated 


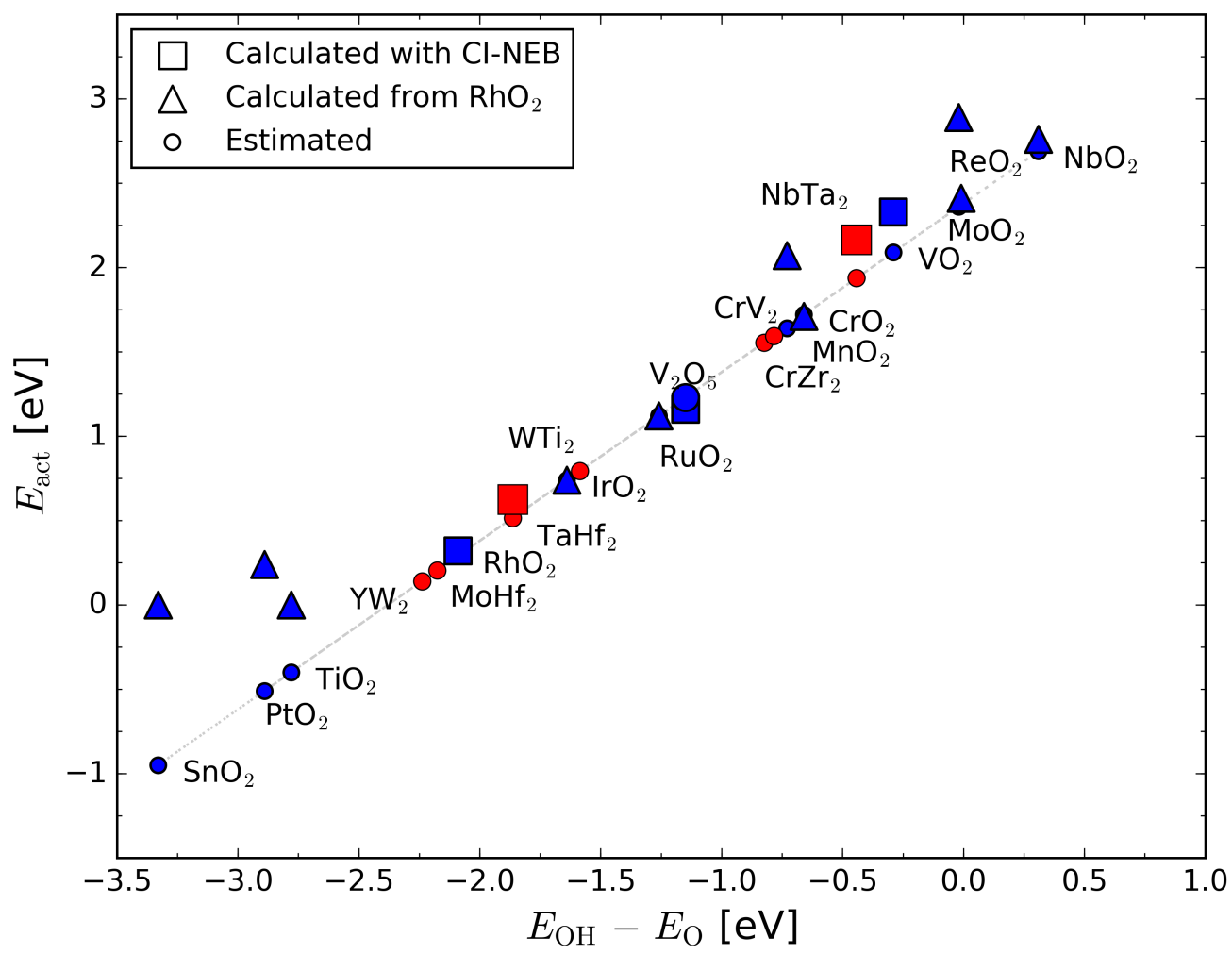

Fig. 6 The activation energy of methane activation plotted as a function of the descriptor $E_{\mathrm{OH}}-E_{\mathrm{O}}$. The $M$ Xenes are plotted in red and the MeO $\mathrm{O}_{2}$ in blue. Squares denote activation energies obtained using the CI-NEB method, triangles activation energies obtained using the optimized reaction path found on the $\mathrm{RhO}_{2}$ structure and circles denote the estimated activation energy according to Eq. (17).

activation energies are found to be in reasonably good agreement with the estimated values using the very simple expression in Eq. (17). For $\mathrm{RhO}_{2}, \mathrm{IrO}_{2}, \mathrm{RuO}_{2}, \mathrm{CrO}_{2}, \mathrm{~V}_{2} \mathrm{O}_{5}$ and $\mathrm{TaHf}_{2} \mathrm{C}_{2} \mathrm{O}_{2}$ the estimate is excellent with a deviation below $0.1 \mathrm{eV}$ from the calculated value. For $\mathrm{ReO}_{2}, \mathrm{NbO}_{2}$ and $\mathrm{NbTa}_{2} \mathrm{C}_{2} \mathrm{O}_{2}$ the deviation is slightly below $0.2 \mathrm{eV}$ and for $\mathrm{MnO}_{2}, \mathrm{VO}_{2}$ and $\mathrm{MoO}_{2}$ the deviation is above $0.3 \mathrm{eV}$. For $\mathrm{SnO}_{2}, \mathrm{PtO}_{2}$ and $\mathrm{TiO}_{2}$ the estimation for the activation energy is below $0.0 \mathrm{eV}$ i.e. indicating formation of has no kinetic barrier. The calculated activation energy is found to be very low or $0.0 \mathrm{eV}$ in agreement with that. The data in Fig. 6 can also be interpreted as the potential vs. rate i.e. the applied potential needed to run the reaction vs. rate of methanol production. As higher potential is applied (more negative $E_{\mathrm{OH}}-E_{\mathrm{O}}$ values) the lower the energy barrier for methanol formation becomes and oppositely if low potential is applied (more positive $E_{\mathrm{OH}}-E_{\mathrm{O}}$ values) the activation energy increases, lowering the rate for methanol production at a given temperature.

$\mathrm{IrO}_{2}, \mathrm{RuO}_{2}, \mathrm{WTi}_{2} \mathrm{C}_{2} \mathrm{O}_{2}$ and $\mathrm{TaHf}_{2} \mathrm{C}_{2} \mathrm{O}_{2}$ were found to have $\Delta G_{2}$ as the potential limiting step and relatively low overpotential. Consequently, they are found to have an activation energy of reasonable magnitude, in order for the methanol production reaction to run at a sufficient rate at a given temperature. The more oxidized structure, $\mathrm{V}_{2} \mathrm{O}_{5}$, appears on the left side of the volcano in Fig. 5 but $E_{\mathrm{O}}-E_{\mathrm{OH}}$ is not a good descriptor for it as $\mathrm{OH}$ very weakly bonded (Fig. 3). Therefore, it is the first step, $\Delta G_{4}=G_{\mathrm{OH}}$ which is the potential determining step and consequently $\mathrm{O}$ is never present on the surface on $\mathrm{V}_{2} \mathrm{O}_{5}$. In ref. 13 , 1 wt. $\% \mathrm{~V}_{2} \mathrm{O}_{5}$ on
$\mathrm{SnO}_{2}$ was found to have the highest methanol production. Pure $\mathrm{SnO}_{2}$ i.e. $0 \dot{\mathrm{w} t} \% \% \mathrm{~V}_{2} \mathrm{O}_{5}$ no methanol was produced and pure $\mathrm{V}_{2} \mathrm{O}_{5}$ i.e. $100 \mathrm{wt} . \% \mathrm{~V}_{2} \mathrm{O}_{5}$ methanol was produced but in much lower quantities than on $1 \mathrm{wt} . \% \mathrm{~V}_{2} \mathrm{O}_{5}$. The results presented here are partially in agreement what we find, $\mathrm{SnO}_{2}$ is found on the right leg on the OER volcano (Fig. 4) with the potential limiting step the formation of oxygen on the surface and consequently negligible methanol production activity. The $\mathrm{V}_{2} \mathrm{O}_{5}$ shown here is a $\mathrm{V}_{2} \mathrm{O}_{5}(001)$ surface which according to our calculations is not an active methanol catalyst but another surface termination or steps/defects on $\mathrm{V}_{2} \mathrm{O}_{5}(001)$ could potentially have different energetics and consequently activity towards methanol production.

Having established a linear relation between the activation energy for methanol production and the descriptor $E_{\mathrm{OH}}-E_{\mathrm{O}}$ it is possible to investigate the rate of methanol production vs. oxygen evolution as function of the oxygen binding energy by a kinetic model. Assuming the scaling relations hold for the OER reaction i.e. $G_{\mathrm{O}} \simeq 2 G_{\mathrm{OH}}$ and $G_{\mathrm{OOH}}=G_{\mathrm{OH}}+3.2 \mathrm{eV}$ the activation energy for the two reactions can be written as

$$
\begin{aligned}
& E_{\mathrm{act}}^{\mathrm{CH}_{3} \mathrm{OH}}=-\frac{1}{2} G_{\mathrm{O}}+2.4 \\
& E_{\mathrm{act}}^{\mathrm{O}_{2}}(U)=-\frac{1}{2} G_{\mathrm{O}}+3.2-e U
\end{aligned}
$$

where the constant 2.4 in Eq. (19) comes from Eq. (17) and activation energy for oxygen evolution is assumed to be energy needed to form $* \mathrm{OOH}$ from $* \mathrm{O}$. This corresponds to a lower limit 
of the activation energy and any additional $\mathrm{O}_{2}$ evolution energy barrier will increase the selectivity towards methanol formation. To keep the kinetic model simple but still capturing the important chemistry we consider the following reactions

$$
\begin{gathered}
*+\mathrm{H}_{2} \mathrm{O} \underset{k_{1}^{-}}{\stackrel{k_{1}^{+}}{\longrightarrow}} * \mathrm{O}+2\left(\mathrm{H}^{+}+\mathrm{e}^{-}\right) \\
* \mathrm{O}+\mathrm{CH}_{4} \stackrel{k_{2}^{+}}{\longrightarrow} *+\mathrm{CH}_{3} \mathrm{OH} \\
* \mathrm{O}+\mathrm{H}_{2} \mathrm{O} \stackrel{k_{3}^{+}}{\longrightarrow} *+\mathrm{O}_{2}+2\left(\mathrm{H}^{+}+\mathrm{e}^{-}\right)
\end{gathered}
$$

from where we find that

$$
\begin{aligned}
R_{\mathrm{CH}_{3} \mathrm{OH}} & =p_{\mathrm{CH}_{4}} k_{2}^{+} \theta_{* \mathrm{O}}=\frac{p_{\mathrm{CH}_{4}} p_{\mathrm{H}_{2} \mathrm{O}} k_{2}^{+} K_{1}(U)}{1+p_{\mathrm{H}_{2} \mathrm{O}} K_{1}(U)} \\
R_{\mathrm{O}_{2}} & =p_{\mathrm{H}_{2} \mathrm{O}} k_{3}^{+}(U) \theta_{* \mathrm{O}}=\frac{p_{\mathrm{H}_{2} \mathrm{O}^{2}} k_{3}^{+}(U) K_{1}(U)}{1+p_{\mathrm{H}_{2} \mathrm{O}} K_{1}(U)}
\end{aligned}
$$

with

$$
K_{1}=\frac{k_{1}^{+}}{k_{1}^{-}} \quad k_{2}^{+}=\frac{k_{B} T}{h} \exp \frac{E_{\mathrm{act}}^{\mathrm{CH}_{3} \mathrm{OH}}}{k_{B} T} \quad k_{3}^{+}(U)=\frac{k_{B} T}{h} \exp \frac{E_{\mathrm{act}}^{\mathrm{O}_{2}}(U)}{k_{B} T}
$$

The rate constant, $k_{2}^{+}$, in Eq. (22) does not depend on the applied potential as this is a purely thermal heterogeneous catalytic step where as the rate constant for the reaction in Eq. (23), $k_{3}$, depends on the applied potential. In Fig. 7 the rates for methanol production and oxygen evolution are plotted as a function of the binding energy of $\mathrm{O}, E_{\mathrm{O}}$, at for $p_{\mathrm{H}_{2} \mathrm{O}}=p_{\mathrm{CH}_{4}}=0.5$ $\left(p_{\mathrm{H}_{2} \mathrm{O}}+p_{\mathrm{CH}_{4}}=1\right)$ and two different temperatures, $300 \mathrm{~K}$ and $400 \mathrm{~K}$. It is important to note that the coverage of $* \mathrm{O}$ is kept fixed by applying a potential of $U=1 / 2 e G_{O}$ and thereby assuring that $G_{\mathrm{O}}(U)=0 \mathrm{eV}$. The standard cell potentials for methanol production according to reaction (1) and OER are $-0.63 \mathrm{~V}$ (RHE) and $-1.18 \mathrm{~V}$ (RHE) assuming water to react from the gas phase, respectively. Consequently the rate for the two reactions is zero at potentials below $0.63 \mathrm{~V}$ (RHE) and $1.18 \mathrm{~V}$ (RHE) corresponding to $G_{\mathrm{O}}=1.3 \mathrm{eV}$ and $G_{\mathrm{O}}=2.36 \mathrm{eV}$ respectively as $\Delta G$ for each reaction is positive in this regime and equilibrium is towards the reactants rather than the products. From Fig. 7it is clear that the rate of methanol production increases as the binding energy of oxygen on the surface decreases i.e. oxygens binds weaker to the surface. At $U=1.18 \mathrm{~V}\left(G_{\mathrm{O}}=2.36 \mathrm{eV}\right)$ the oxygen evolution becomes viable (for an ideal OER catalyst having zero overpotential) and runs at higher rate than methanol production as the activation energy is lower for the former. When $G_{\mathrm{O}}>3.2 \mathrm{eV}$ the activation energy for oxygen evolution is zero which first happens at $G_{\mathrm{O}}>4.75 \mathrm{eV}$ for the methanol production. For $\mathrm{G}_{\mathrm{O}}>3.2 \mathrm{eV}$ there is no methanol production as $\Delta G_{3,4}$ becomes the potential limiting step and therefore $* \mathrm{O}$ is not present on the surface to react further with methane. Increasing the temperature by $100 \mathrm{~K}$ enhances the methanol production rate by several orders of magnitude depending on the oxygen binding energy where as the effect is much less pronounced for the OER as its activation energy is much lower. By use of geometric effects the difference in binding energy of $\mathrm{OOH}$ and $\mathrm{O}$ can be tuned in order to diminish the rate of the oxygen evolution reaction and consequently enhance the selectivity towards the methanol reaction pathway. $24 \sqrt{25}$

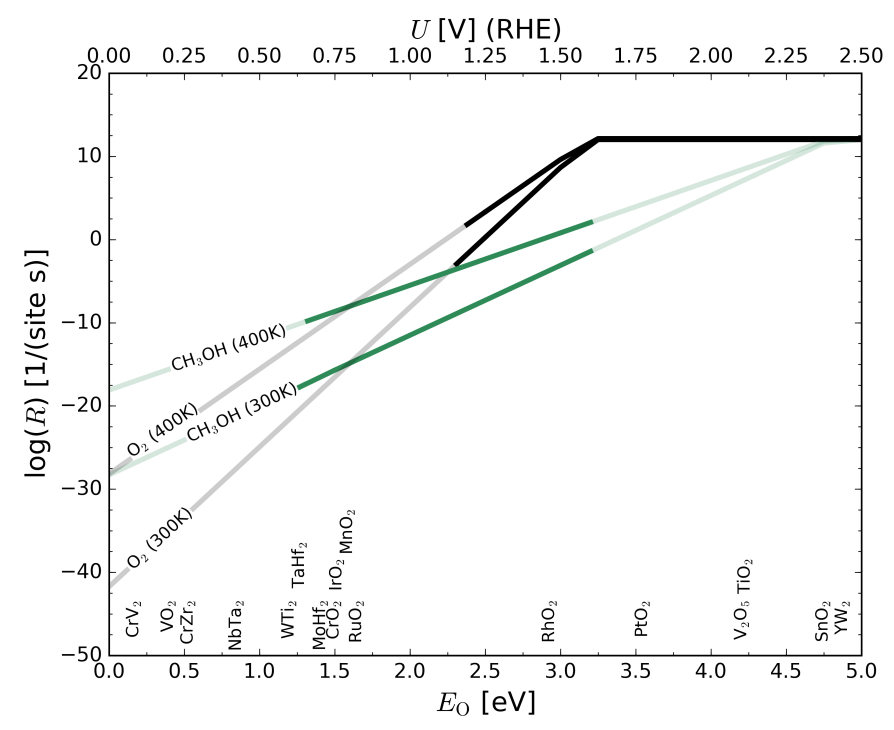

Fig. 7 The rates for the OER (black) and methanol production (green) plotted according to Eq. (24) and (25) at $300 \mathrm{~K}$ and $400 \mathrm{~K}$. The rates are plotted for a fixed coverage of $* \mathrm{O}$ with $G_{\mathrm{O}}(U)=0 \mathrm{eV}$ by applying a potential of $U=1 / 2 e G_{O} \mathrm{~V}$. The names of the materials considered here are marked along the bottom $x$-axis. The upper $x$-axis does as such denote the minimum required applied potential for oxygen adsorption on a specific surface.

\section{Conclusion}

The production of methanol via an electrochemical process is found to be viable by considering a range of different rutile $\mathrm{MeO}_{2}$ (110) surfaces and $\mathrm{AB}_{2} \mathrm{C}_{2} \mathrm{O}_{2}$ MXenes as electrocatalysts. A fundamental surface catalytic limitation in terms of a compromise between selectivity and activity of the methanol production is identified. By changing the catalytic surface it is possible to tune the reactivity of an adsorbed oxygen atom. This is shown to correlate with the activation energy required to activate methane. A less stable oxygen binding catalyst, i.e. a catalyst providing a more reactive oxygen, results in a lower energy barrier to overcome. Consequently, a higher potential needs to be applied. A kinetic model validates the hypothesis that the rate for methanol production increases with weaker oxygen binding but in order to acquire sufficient selectivity the applied potential should not allow the full OER reaction to proceed. The candidates that fulfil the necessary criteria, i.e. have $\mathrm{OOH}$ adsorption as the potential limiting step $\left(G_{\mathrm{O}}-G_{\mathrm{OH}}<1.6 \mathrm{eV}\right)$ and $1.3 \mathrm{eV}<G_{\mathrm{O}}<3.2 \mathrm{eV}$, and have reasonable activation energy at suitable temperatures are $\mathrm{IrO}_{2}, \mathrm{RuO}_{2}, \mathrm{RhO}_{2}, \mathrm{WTi}_{2} \mathrm{C}_{2} \mathrm{O}_{2}$ and $\mathrm{TaHf}_{2} \mathrm{C}_{2} \mathrm{O}_{2}$. Only a small subset of the MXenes have been studied here, but the performance warrants a larger study. By varying the number of layers, the composition of the transition metals and surface terminations, we expect to find candidate materials with a more optimal binding to $\mathrm{O}$ and $\mathrm{OH}$. As such, we anticipate there is ample room for improvement of the catalysis of this important reaction. 


\section{Computational Details}

All calculations were performed using the Grid-based Projector Augmented Wave (GPAW) program ${ }^{2627}$ with the Atomic Simulation Environment (ASE) interface 26 .

For the $\mathrm{MeO}_{2}$ structures: Exchange and correlations (XC) were modelled on the Generalized Gradient Approximation (GGA) level, using the XC-functional, BEEF-vdW 28 , and grid spacing of $h=0.18 \AA$. The unit cell of the rutile (110) metal oxide slabs consisted of four tri-layers, in total 24 metal atoms and 48 oxygen atoms corresponding to a $(1 \times 3)$ surface unit cell. A k-point mesh of $(3 \times 3 \times 1)$ was used to sample the Brilloin zone.

For the MXenes: The PBE ${ }^{29}$ XC-functional was used and a plane wave cutoff of $800 \mathrm{eV}$ employed. The $2 \times 2$ unit cell was used, resulting in 28 atoms. A k-point mesh of $(9 \times 9 \times 1)$ was necessary. The unit cell of each material was optimised using the UnitCellFilter method available in the ASE package 30 . To model the transition state and obtain activation energies the Nudged Elastic Band method with the climbing image (CI-NEB) variation as implemented in ASE was used ${ }^{31 / 32}$. The Gibbs free energies of the OER reactions were calculated according to the methods described in ref. $\frac{20}{20}$. For calculating the rate in Fig. 7 as a function of temperature we used $\mathrm{H}_{2} \mathrm{O}(\mathrm{g})$ and $\mathrm{H}_{2}(\mathrm{~g})$ as references and the zero-point for $* \mathrm{O}$ from ref. 20 to obtain the free energies. All structures along with total energies will be available on Jan Rossmeisl' group webpage (http://nano.ku.dk/english/research/ theoretical-electrocatalysis/katladb/).

\section{Acknowledgements}

We acknowledge support from the Danish Council for Independent Research Sapere Aude Program, Grant No. 11-1051390, research grant 9455 from VILLUM FONDEN and Innovation Fund Denmark (grand solution ProActivE 5124-00003A). The Center for Nanostructured Graphene is sponsored by the Danish National Research Foundation, Project DNRF58.

\section{Conflict of interest}

There are no conflicts to declare.

\section{References}

1 US Energy Information Administration, http://www.eia.gov/ naturalgas, Accessed: 2014.

2 International Energy Agency. Key World Statistics, 2014.

3 P. Forster, V. Ramaswamy, P. Artaxo, T. Berntsen, R. Betts, D. Fahey, J. Haywood, J. Lean, D. Lowe, G. Myhre, J. Nganga, M. S. R. P. G. Raga and R. V. Dorland, Changes in Atmospheric Constituents and in Radiative Forcing, 2007.

4 M. H. Ab Rahim, M. M. Forde, C. Hammond, R. L. Jenkins, N. Dimitratos, J. A. Lopez-Sanchez, A. F. Carley, S. H. Taylor, D. J. Willock and G. J. Hutchings, Topics in Catalysis, 2013, 56, 1843-1857.

5 R. Palkovits, M. Antonietti, P. Kuhn, A. Thomas and F. Schüth, Angewandte Chemie International Edition, 2009, 48, 69096912.

6 N. Agarwal, S. J. Freakley, R. U. McVicker, S. M. Althahban, N. Dimitratos, Q. He, D. J. Morgan, R. L. Jenkins, D. J.
Willock, S. H. Taylor, C. J. Kiely and G. J. Hutchings, Science, 2017, 358, 223-227.

7 Z. Liang, T. Li, M. Kim, A. Asthagiri and J. F. Weaver, Science, 2017, 356, 299-303.

8 D. K. Pappas, E. Borfecchia, M. Dyballa, I. A. Pankin, K. A. Lomachenko, A. Martini, M. Signorile, S. Teketel, B. Arstad, G. Berlier, C. Lamberti, S. Bordiga, U. Olsbye, K. P. Lillerud, S. Svelle and P. Beato, Journal of the American Chemical Society, 2017, 139, 14961-14975.

9 M. Behrens, F. Studt, I. Kasatkin, S. Kühl, M. Hävecker, F. Abild-Pedersen, S. Zander, F. Girgsdies, P. Kurr, B.-L. Kniep, M. Tovar, R. W. Fischer, J. K. Nørskov and R. Schlögl, Science, 2012.

10 K. W. Frese, Langmuir, 1991, 7, 13-15.

11 A. Tomita, J. Nakajima and T. Hibino, Angewandte Chemie International Edition, 2008, 47, 1462-1464.

12 G. Psofogiannakis, A. St-Amant and M. Ternan, The Journal of Physical Chemistry B, 2006, 110, 24593-24605.

13 B. Lee and T. Hibino, Journal of Catalysis, 2011, 279, 233 240.

14 Y. E. Seidel, A. Schneider, Z. Jusys, B. Wickman, B. Kasemo and R. J. Behm, Langmuir, 2010, 26, 3569-3578.

15 M. Naguib, J. Come, B. Dyatkin, V. Presser, P.-L. Taberna, P. Simon, M. W. Barsoum and Y. Gogotsi, Electrochemistry Communications, 2012, 16, $61-64$.

16 Z. W. Seh, J. Kibsgaard, C. F. Dickens, I. Chorkendorff, J. K. Nørskov and T. F. Jaramillo, Science, 2017, 355, eaad4998.

17 M. Naguib, M. Kurtoglu, V. Presser, J. Lu, J. Niu, M. Heon, L. Hultman, Y. Gogotsi and M. W. Barsoum, Advanced Materials, 2011, 23, 4248-4253.

18 M. Pandey and K. S. Thygesen, The Journal of Physical Chemistry C, 2017, 121, 13593-13598.

19 M. Busch, N. B. Halck, U. I. Kramm, S. Siahrostami, P. Krtil and J. Rossmeisl, Nano Energy, 2016, 29, 126 - 135.

20 J. K. Nørskov, J. Rossmeisl, A. Logadottir, L. Lindqvist, J. R. Kitchin, T. Bligaard and H. Jonsson, The Journal of Physical Chemistry B, 2004, 108, 17886-17892.

21 R. L. Doyle and M. E. G. Lyons, in The Oxygen Evolution Reaction: Mechanistic Concepts and Catalyst Design, ed. S. Giménez and J. Bisquert, Springer International Publishing, Cham, 2016, pp. 41-104.

22 Z. W. Seh, J. Kibsgaard, C. F. Dickens, I. Chorkendorff, J. K. Nørskov and T. F. Jaramillo, Science, 2017, 355, eaad4998.

23 A. A. Latimer, H. Aljama, A. Kakekhani, J. S. Yoo, A. Kulkarni, C. Tsai, M. Garcia-Melchor, F. Abild-Pedersen and J. K. Nørskov, Phys. Chem. Chem. Phys., 2017, 19, 3575-3581.

24 J. H. Montoya, L. C. Seitz, P. Chakthranont, A. Vojvodic, T. F. Jaramillo and J. K. Nørskov, Nature Materials, 2016, 16, 7081.

25 J. K. Nørskov, T. Bligaard, B. Hvolbaek, F. Abild-Pedersen, I. Chorkendorff and C. H. Christensen, Chem. Soc. Rev., 2008, 37, 2163-2171.

26 A. H. Larsen, J. J. Mortensen, J. Blomqvist, I. E. Castelli, R. Christensen, M. Dułak, J. Friis, M. N. Groves, B. Ham- 
mer, C. Hargus, E. D. Hermes, P. C. Jennings, P. B. Jensen, J. Kermode, J. R. Kitchin, E. L. Kolsbjerg, J. Kubal, K. Kaasbjerg, S. Lysgaard, J. B. Maronsson, T. Maxson, T. Olsen, L. Pastewka, A. Peterson, C. Rostgaard, J. Schiøtz, O. Schütt, M. Strange, K. S. Thygesen, T. Vegge, L. Vilhelmsen, M. Walter, Z. Zeng and K. W. Jacobsen, Journal of Physics: Condensed Matter, 2017, 29, 273002.

27 J. J. Mortensen, L. B. Hansen and K. W. Jacobsen, Phys. Rev. $B, 2005,71,035109$.

28 J. Wellendorff, K. T. Lundgaard, A. Møgelhøj, V. Petzold, D. D. Landis, J. K. Nørskov, T. Bligaard and K. W. Jacobsen, Phys. Rev. B, 2012, 85, 235149.
29 J. P. Perdew, K. Burke and M. Ernzerhof, Phys. Rev. Lett., 1996, 77, 3865-3868.

30 S. Bahn and K. Jacobsen, Computing in Science and Engineering, 2002, 4, 56-66.

31 H. Jonsson, G. Mills and K. W. Jacobsen, in Classical and Quantum Dynamics in Condensed Phase Simulations, ed. B. J. Berne and G. Cicotti, World Scientific, 1998, ch. Nudged elastic band method for finding minimum energy paths of transitions, pp. 385-404.

32 G. Henkelman, B. P. Uberuaga and H. Jonsson, The Journal of Chemical Physics, 2000, 113, 9901-9904. 